\title{
El porvenir político-cultural y escatológico del hombre según Paul Ricoeur: utopía y ontología
}

\author{
MAURICIO BEUCHOT \\ UNAM, México
}

\section{Introduccion}

En este trabajo queremos abordar algo que se ha mostrado como distintivo de la hermenéutica ricoeuriana, a diferencia de otras hermenéuticas, señaladamente la del psicoanálisis, así como de otros planteamientos sobre la conducta moral y política del hombre, a saber: la atención no sólo a la arqueología del sujeto humano, sino también a su teleologia o escatologia. Ricoeur, partiendo de su antropología filosófica y su hermenéutica, se cuestiona sobre el futuro del hombre, sobre su teleologia o escatologia final.

La razón de esto la vemos en una constatación sencilla y muy evidente, casi cotidiana. De manera insistente, pero no de manera morbosamente obsesiva, sino muy real, se le plantea al hombre la pregunta por el futuro. Han surgido muchos augures, muchos adivinos y predictores. Pero en verdad ha habido pocos profetas auténticos. Porque, a pesar de la idea que suele tenerse ordinariamente del profeta, no es tanto aquel que vaticina o dice lo que va a suceder, ni cómo va a ser muestro futuro y cómo serán los desastres que van a acompañarlo. Sino que más bien el auténtico profeta, según lo que se piensa en la tradición judeocristiana, es el que sabe decirnos qué sentido tiene el presente, desde un pasado originario, y hacia dónde va en definitiva. Al filósofo le ha tocado un difícil papel de profeta. $Y$ nos parece pertinente ver cómo Ricoeur ha tratado de curnplir con este papel. Trataremos de explicitar su rellexión en tres momentos. Primeramente, el establecimiento de la pre- gunta por el futuro de la historia social desde la historia individual, personal, concreta. En segundo higar, la dialéctica que rige el desenvolvimiento de esta pregunta. $Y$, en tercer lugar, la posibilidad de una respuesta teórico-práctica.

\section{El futuro, desde el pasado $y$ el presente}

Ricoeur insiste en la radical historicidad del hombre, pero aclara que es una historicidad que, a su vez, está radicada en el ser. Tiene sustento ontológico. Contiene un sentido, que vamos a un tiempo descubriendo, previendo y realizando. No sólo es un sentido arbitraxiamente elegido. Podríamos decir: es un origen que nos marca profundamente para desarrollarlo como proyecto hacia el futuro.'

Con esta alusión al origen, a lo natural, a lo no-arbitrario, nuestra pregunta se transforma. Habiendo comenzado por cuestionar de manera muy simplista el futuro: ¿qué nos espera en el porvenir?, ahora la pregunta reviste otra forma ya no tan abstracta: ¿hacia dónde vamos orientando nuestro origen, haciéndole presente que se dirige al porvenir? Nos lanza a un futuro como proyecto cultural e histórico, pero también es una pregunta acerca de una postura originaria. Nos prende desde el origen. ¿Cuál es este origen? Este origen es algo que lleva un nombre muy desprestigiado en nuestra actual cultura tecnócrata y pragmatista. Es una afirmación ontológica' originaria. Pero, aunque parece muy abstracta y hasta abstrusa (por involucrar el nombre «ontologían), está 
inviscerada en lo más concreto que hay, es decir, en esa persona que somos. Es algo $\sin$ lo cual la historia, nuestra historia, y nuestra vida se nos volverían ambigüedad, carencia de sentido, ansiedad y negatividad. Sin una afirmación original ontológica desde la persona y la valoración de la persona, el género humano, con su cultura y sus construcciones $-\mathrm{y}$, sobre todo, con sus individuos humanos concretos- cae en el sinsentido, en la angustia y la ansiedad: en la negatividad autodestructiva. Pero, justamente, la afirmación ontológica se levanta desde nuestra negatividad (ya vencida), y todo eso porque mira a un sentido. De inmediato se dirá: ¿qué sentido? Y el sentido, según Paul Ricoeur, es una tensión desde lo que él llama la arqueología de la historia hasta la escatología de la historia. Es decir, sólo hay cabal sentido cuando le da al hombre una perspectiva de plenitud personal en el contexto de la sociedad. Tal es el sentido. Sentido que, por lo que se ve, está muy lejos del cauce factual que va llevando la historia, nuestra historia.

La historia que contempla Ricoeur va avanzando en diversos campos: científico, técnico, filosófico-humanista. Y cada cambio de un sector afecta a los demás. Por cjemplo, es hasta trivial anotar que la mecanización de ciertas funciones del pensamiento mediante la cibernética puede influir en el ser humano, e incluso distorsionar su imagen y su noción. Tenemos también las predicciones apocalípticas de los ecologistas, los enigmas que nos depara la biología, y la aplicación de técnicas de control psicológico y social. Pero ninguno de estos campos puede explicitar el sentido de la historia, del hombre. Da la impresión de que vivimos un mito: el del pragreso; un mito malo. Nos hace pensar en un progreso vertiginoso y acelerado, pero las más de las veces sin ton ni son; y se vive en la creencia de que lo importante es progresar. Pero, ¿hacia dónde? El concepto más extendido de progreso -el de la ciencia y la técnica- se ha revelado como un mito en cierta medida perverso, precisamente por su incapacidad de aclarar su propio sentido y derrotero. Todavia los mitos en buen sentido tenían como función brindar sentido a la colectividad, eran la vivencia comunitaria del sentido de la vida.

$Y$ ahora el progreso, o el mito negativo del progreso, cumple una función contraria: la de llenamos de angustias y temores. Y, si la admiración, que es el inicio del filosofar, se ve oprimida por la angustia, si se ve ahogada en ella, se frustra el proceso filosófico. Simplemente el hombre se siente incapaz de filosofar sobre aquello que lo oprime de manera agobiante. Le resulta amenazador. Hay, por eso, que balancear esta ansiedad ante el futuro con un ingrediente de paz.

Ricoeur encuentra como tal ingrediente de paz la esperanza. Pero, nos advierte, la esperanza estática no basta, no alcanza a apaciguar; tiene que ser esperanza activa: es necesaria la posesión teórico-práctica (i. e. la conceptualización y la vivencia) de una escatología, o, usando otro término aproximado, una teleología histórica, ya sea real o utópica. ${ }^{2}$

La teleologia, escatología o finalidad nos pone en tensión. Y la tensión siempre es paradoja, es una especie de contradicción; por una parte, vivimos lo no deseado; por otra parte, la libertad va construyéndonos su ámbito deseado. De ahí que Ricoeur llame al hombre ula paradoja viviente".

De manera bastante pascaliana, nos está diciendo que el hombre se trasciende continuamente a sí mismo. Esto no es un lenguaje pedante y críptico, apunta a una realidad: el hombre debe mantener su conciencia abierta, en estado de alerta, para superar sucesivamente los segmentos de tiempo transcurridos, 
que corren en el presente, y entrar así en una temporalidad humana, propiamente historica.

Van sucediendo muchas cosas, a nivel económico, a nivel político, a nivel social: modemidad, postmodernidad, etc; y todas estas cosas tienen implicaciones éticas y antropológicas. Pero todas ellas -como lo ve Ricoeur - llevan, al igual que lo antropológico y lo ético, una carga ontológica que consiste en el modo de existencializar nuestra esencia. Es decir, todo esto fundamenta, para Paul Ricoeur, una filosofía de la historia. Pero, aunque la historia se ha concebido como pasado, Ricoeur quiere ampliarla de modo que también afecte al presente y al futuro. Es decir, está implicando los origenes -l pasado-y desplegándose en el presente hacia el futuro. Es cierto que el pasado ya no existe, y que el futuro todavía no es; pero el presente, por el pasado, está preñado de porvenir. Tampoco ésta es sólo una frase bella y sugestiva, sino una de esas expresiones vigorosas que encontramos en Ricoeur. Indica que los frecuentes sinsentidos que arrastra la historia humana pueden llenarse de sentido en el presente para ir siendo modificados por el hombre, a causa de la presignificación del futuro con que se los dota. Y en ello el filosofo tiene una gran parte, pues interpreta el sentido que van teniendo los acontecimientos, integrando su pensamiento en ellos y a ellos en su pensamiento, aunque lo haga desde una perspectiva filosófica determinada (y restringida, por lo mismo) en la historia. Así, por ejemplo, si el tomismo está vivo en la actualidad, no lo está al modo como bo estuvo en la Edad Media; se integra a un nuevo cúmulo de acontecimientos que son otros tantos incentivos para su reflexión. De esta manera Ricoeur ha podido revitalizar, con su hermenéutica filosófica o filosofía hermenéutica, una idea muy querida para Leibniz: la de la Filosofía Perenne. Desde ella dinamiza y desarrolla la pregunta por el futuro del hombre.

\section{La filosofia como hemenéutica del acontecimiento y de la palabra}

¿Cuál es, concretamente, la labor del filosofo frente al problema del futuro? Para Ricoeur, es una interpretación orientadora de la sociedad a la luz del ser, de la verdad y del bien. Pero la interpretación filosófica (ontológica, antropológica y ética) es asunto muy dificil, por no ser un asunto ostentoso y directamente práctico. No influye fácilmente en la sociedad. Por eso Ricoeur compara su método con la uno-violencia» en la historia de las formaciones del poder político. ${ }^{3} \mathrm{Y}$ que, sin embargo, puede ser altamente influyente en el movimiento histórico, al modo como la no-violencia se vuelve transformación y revolución honda, porque, a pesar de su lentitud, alude a la profundidad e integrablidad del ser humano: alude a todo el hombre en la sociedad. Pero, en la interacción del hombre con la sociedad se revela la finitud, dado que siempre quedará algo por hacer; más aún, quedará siempre mucho por realizar. Sin embargo, esto es bueno, porque dinamiza al hombre dentro del cúmulo de las posibilidades que se van realizando hacia el futuro.

A pesar de ser no-violenta, la tarea que Ricoeur asigna al filosofo nos muestra que el filósofo mismo resulta molesto para los hombres instalados y satisfechos. Cuestiona la marcha de los acontecimientos. Llama a la conciencia, busca que el hombre aprenda a interpretar. Y en la interpretación se da la reflexión. Se busca el auténtico camino del ser, ahora manifestado como camino del hombre histórico; pues, de alguna manera, el hombre lo tiene en sus manos. Es así como puede hablarse en Ricoeur de una eontología militante». 
Se abraza desde cl principio una ontología, y se va realizando conforme avanza la vida. Con un dejo de reproche, frecuentemente se dice que el filosofo debe influir de manera más directa, concreta y práctica en los procesos sociales. Sí, dice Ricoeur, pero debe hacerlo sobre todo desde un nivel sapiencial, iluminando con su interpretación y su teoría el proceso mismo, esclareciendo la mejor finalidad, dando una teleología esperanzadora $y$ viva, $y$ que promueva el bien de la humanidad.

Mencionaremos un aspecto en el que Ricoeur desea ser profeta, interpretar e iluminar el provenir, y presentarse como filósofo que llama a una praxis consciente, en estado de vigilia: es su oposición al positivismo ingenuo que alimenta la idea de un progreso histórico universal y univoco en su filosofía de la historia. $\mathrm{Ri}$ coeur considera que la esperanza cristiana de la salvación y la creencia en un progreso indefinido y vago nunca pueden coincidir. Pues el progreso así entendido, de manera simplista y unilateral, únicamente puede ocurrir en el nivel inferior de la historia, el del instrumento, ya sea tenido como herramienta, ya sea tenido por algo así como la acumulación del conocimiento; pues se cierne en un dominio de acontecimientos racionales y abstractos, es decir, fuera del contacto con los acontecimientos humanos; mientras que, en otro polo de la historia, se encuentra el ámbito de los acontecimientos humanos, que son existenciales y polisémicos, los cuales las más de las veces no son tan racionales y no exhiben ningún progreso. La única manera de superar esta contradicción es presentar, como una síntesis futura, una finalidad de esa historia y de ese asíllamado "progreso", un éskhaton (como le llamó la teología griega), que es supraracional, a saber, el advenimiento de lo que la tradición cristiana ha llamado «el Reino de Dios», que -conjuntando la utopía con la necesidad real- consiste en justicia, paz y alegría.

Lo que Ricoeur ha designado como afirmación ontológica tiene mucho que ver con la historia del progreso de los instrumentos del hombre, las herramientas con las que el hombre se aprovisiona cada vez en mayor escala e in. tensidad. Pero se relaciona con el progreso material desde un ámbito más elevado, pues también pretende integrar con lo anterior la historia concreta humana de la ambigüedad existencial. Lo hace desde una reflexion sobre la esperanza activa del hombre, que, aun cuando es suprarracional (teológico), guía el razonamiento y la acción. Los guía hacia esa finalidad esperanzadora, optimista y optima que Ricoeur ha llamado ala síntesis pospuesta». Es pospuesta porque siempre se nos da parcialmente, siempre queda mucho por hacer. ${ }^{4} \mathrm{Y}$ tal síntesis es el bien común de la humanidad.

Así, la afirmación ontológica ricoeuriana es más que una mera negación de la negación primeriza y además finita. Más que una denegación, como ncgación de la negación, es también positiva y ontológicamente una posición del Bien y de lo valioso, además del ser. Una postura que constantemente trasciende y sobrepasa tanto la ambigüedad de la existencia humana concreta, como también los acontecimientos sociales. Como tal, propone una esperanza, una finalidad concreta, un éskhaton. Por lo cual, lo que es el Fin, lo teleológico pleno, el Eskhaton, es también el verdadero Origen de la afirmación del ser. Es casi como un círculo, o más bien como una espiral que dinamiza la historia.

\section{La respuesta teórico-práctica concreta de Ricoeur sobre el futuro del hombre}

Ricoeur sitúa su respuesta a la pregunta por el porvenir del hombre en la dimensión política. Ahora bien, ¿cómo se co- 
nectan lo político y el porvenir del hombre? Ante todo, como algo que alude al sujeto humano, a la persona. Así, Ricoeur considera como un reto y una paradoja la revolución, personalista y $\mathrm{co}-$ munitaria a la vez, que debe hacer el hombre para afrontar adecuadamente el porvenir. Es paradoja porque pone en tensión conciliadora la dialéctica del ser finito del hombre y el deseo de lo infinito. $Y$ hay lugar para un compromiso $\mathrm{co}-$ munitario que nos conecta con el ser en la historia. Estamos, pues, ante una paradoja: el futuro sólo será propiamente humano si se compenetran lo personal y lo comunitario.

Pero sería muy triste quedarse sólo con la paradoja, sin la posibilidad de una conciliación. Tal es la utopía completamente irrealizable, que no da esperanza alguna. Aunque las paradojas surgen hasta en la lógica misma, necesitamos un camino para resolverlas. No quedarnos en la mera utopía vacua. Es cierto que la paradoja, aun cuando es algo insoluble, se pasea como por su casa en la lógica. Pero hay que recordar que la paradoja no sólo tiene carácter lógico, sino que tambiên reviste un as" pecto ontológico y ético: como tensión vivida. Esto sí exige una solución -nos dice Ricoeur-, o por lo menos un camino de respuesta, y entonces la verdad, perdiendo bastante su carácter formal o lógico, adquiere un matiz ontológico y ético: andar en el camino, estar encaminado, caminar en la verdad, aunque no se la agote (pues el hombre jamás podrá agotarla). Tal es la gran paradoja de la individualidad y la comunidad; lo personal y lo social; es una paradoja que angustia y exige ser superada. Pero, según Ricoeur, no estamos ante una paradoja que produce una angustia que haya de ser soportada, sino superada. Y la superación de la angustia que provoca esta paradoja se da en la concifiación, que aquí (puesto que se trata del pensar filosófico, y éste es máximamente reflexivo) es una re-conciliación. ${ }^{5}$

El futuro, que se cierne sobre el cielo ontológico del ser y del no ser, es sobre todo algo que se cieme asimismo sobre el cielo ético del Bien y del Mal. Pero esto es todavía abstracto. Aunque la pregunta es concreta: ¿será nuestro futuro bueno o malo? Ricoeur incita a plantearla desde el ángulo de la persona. Ahí pierde su abstracción y se vuelve concreta, viva. Se vive el problema. $\mathrm{Y}$, para que no nos agobie la angustia del futuro, es necesaria la esperanza. Ella nos ayudará. Sin embargo, como dice Ricoeur, la esperanza no reconcilia, sino que consuela. Es por eso por lo que la angustia la acecha siempre, $\mathrm{Y}$ por ello la esperanza no basta, la mera utopia no es suficiente. Con todo, posibilita perspectivas de solución y conciliación. Para ello Ricoeur exige una reflexión de la razón al nivel de una afirmación viviente. Descubrir cuándo la paradoja abandona la discontinuidad y el absurdo, y entonces poder manejarla; pues, de otra manera, no bastarían para disolverla ni la razón, ni la esperanza, ni la necesidad de felicidad; sólo puede resolverla la fidelidad al ser.

La esperanza de respuesta se sitúa como una esperanza prudente, que no busca sistemas dogmáticos ni prácticas totalizantes, prefabricadas de manera arbitraria. La reflexión avanza poco a poco, por parcelas y cuidadosamente. Esta reflexión filosófica sobre el porvenir del hombre abarca tres niveles estructurales: el de una ontología, el de una ética y el de una política. Porque a Ricoeur le resulta claro que sin una ontología no se fundamenta una ética (aunque la mediación la dé la antropología filosófica) y sin una ética no se fundamenta una política. Y a Ricoeur le interesa estructurar -como ya hemos dicho- la historia de manera que abarque los símbolos del pasado, como ar- 
queología, los símbolos del presente, como filosofia reflexiva, y los símbolos del futuro, como escatología. Reflexiona sobre los símbolos, porque ellos condensan la vivencia humana del pasado, del presente y del futuro. ${ }^{6}$

La ontología, la ética y la política desembocan, para Ricoeur, en una Escatologia, es decir, en una esperanza viva de la conciliación entre los hombres que se va realizando a través de la historia y que impregna de futuro el presente. En este sentido consideramos que Ricoeur adopta la postura de profeta. Profeta en el sentido auténtico, que interpreta el camino del hombre hacia el Bien. $Y$ hacia el mejor de los Bienes.

¿Cómo profetiza Ricoeur? No lo hace de manera puramente vaticinadora o adivinatoria, sino desde el fundamento del pasado que se integra a nuestra historia presente. Recogiendo los errores y sufrimientos de la historia pasada para evitar los males que pueden acaecer a la sociedad en el porvenir. Ricoeur es profeta en el sentido de que sabe vibrar al unísono con el pueblo; ¿quién no desea el bien? ¿quién no espera lo mejor para sí mismo y para los demás de la especie humana en el futuro? Ricoeur mueve nuestro ánimo hacia el bien, que es propiamente el fin, y nos hace buscarlo individual y colectivamente, incluso bajo la forma de una política. La solución sera una política progresivamente universal que busque el bien del hombre, y excluya las amenazas apocalipticas que se ciernen sobre el futuro de la humanidad.

Los fundamentos que establece para ello se concatenan unos con otros: a saber, una moral sin ontología sería un puro juego de convenciones aleatorias, combinaciones arbitrarias. $Y$ sólo una ética bien fundada posibilita para la política una pedagogía de la acción, que es lo que conviene tener para abordar el futuro. Porque conviene sobreponer la libertad al determinismo o a la mera ca- sualidad. Y la libertad es lo que está en el núcleo de la pardadoja del porvenir: una cultura, una civilización que refleje un cierto valor absoluto que le dé sentido. Un progreso sin sentido no es un progreso humano. Tiene que estar animado por la teleología humana y por el Éskhaton o destino.

¿Podemos labrar -con la libertadnuestro futuro? ¿Podemos construir nuestro destino? Problema de voluntad, de voluntad libre. Y que inquieta sumamente a Ricoeur. Más que la indiferencia, se presenta el problema de la renuncia o negación de la voluntad, de la negatividad del querer, y esto constituye un abordaje ontológico del problema de la libertad, enfrentada al ser y al no ser. Hay que optar ontológicamente por el ser o el no ser, por el sí o el no, por el bien o el mal. Y - nos advierte Ricoeur- hay que decidirse por un estilo filosófico en $s i$ o en no, y que esté, además, en un registro determinado. Por ello hay que optar por un estilo flosófico en $s i$, y que esté, además, en un registro de alegría y no en un registro de tristeza y angustia.

Este planteamiento es ontológico y político, según califica Maceiras ${ }^{7}$ a la ontología de Ricoeur como una ontología en verdad militante, porque la negatividad o la afirmación originaria con la que afrontemos el futuro es una paradoja ontológica. Es paradoja porque comporta la afirmación y la negación. Es ontológica, porque en ello nos va nuestro ser, y ya desde el origen. Es una paradoja originaria. Pero lo originario sólo recae sobre la afirmación, aunque arrastra elementos negativos. La negación no puede ser originaria, más aún, no origina nada. Este rechazo de la negación abre la puerta a una posibilidad ontológica de superar la paradoja.

Dice Ricoeur: "Hace falta establecer esta proposición inicial: que la experiencia específica de la finitud de lo individual y lo social se presente de entrada 
como una exigencia correlativa de límite y de trascendencia del límite"..$^{8}$ Esto descarta la negatividad del hombre en la sociedad y declara un triple señalamiento de la paradoja política, siempre en tono ontológico; y que vivimos señaladamente como espera del porvenir: "En primer lugar, la paradoja siempre es más que una suerte de instante en el que el estupor se instalaria en la visión; más que un simple choque crítico que trataría de dominar o esclavizar; pues en ello le va al hombre la posibilidad misma de ver el ser o de desviarse de élı. ${ }^{9}$ En segundo lugar, la paradoja politica siempre está vinculada a la idea de finitud: las pasiones desordenadas individuales o sociales son la paradoja humana, producto de la misma finitud humana. La paradoja indica esa finitud, es un índice de ella. Igualmente, la finitud manifiesta a la paradoja, la revela. Se indican su propia imperfección y negatividad. En tercer y último lugar, la paradoja lleva consigo siempre un estado de ruptura, de discontinuidad, de desproporción. $\mathrm{Y}$ todo ello exige marchar hacia la conciliación.

Por eso se reúnen en nosotros todas estas cosas cuando, desde la filosofia política, avizoramos el futuro del hombre. Ya que nos sentimos desproporcionados ante el. Simplemente: a un crecimiento desmesurado de la técnica no ha correspondido un crecimiento proporcional de humanismo.

Pero - nos previene Ricoeur- no hay que precipitarnos en utopias ni en predicciones futuristas para marcarle camino a la libertad que se desembaraza de la negatividad. Más bien, como prudentemente aconseja Ricoeur, démosle una base ontológica desde la superación de la negatividad, del no-ser, por la voluntad de seguir en el ser y al ser, bajo su forma de bien y valor universalísimo. En conclusión, la paradoja política se podrá superar, dándonos un futuro digno de ser vivido por una afirmación de la racionalidad política, una reflexión que Ricoeur hace pasar por Aristóteles, Rousseau y Hegel: lo político trasciende la lucha de clases y se centra en buscar el bien de toda la colectividad; no es sólo una voluntad que busca por la violencia la superación de los conflictos, sino sobre todo es una voluntad y una razón que busca el bien común. Por eso hay también un mal social o político: la renuncia a la búsqueda racional del bien. Consecuente con esto, Ricoeur subsume la política en la filosofia: "La política puede ser reintegrada a la intención fundamental de la filosofia misma, al Bien y a la Felicidad. Hay una manera de ser hombre, a saber, participar en la ética del Bien y de la Felicidad. Así, la originalidad del pensamiento político de Paul Ricoeur consiste en haber anudado en un concepto único lo positivo y lo negativo de lo político. Si la Pólís es Razón, también es Voluntad: si el estado es racional y razonable, avanza, a través de la historia, con múltiples decisiones, thacia el éskhaton o finalidad o valor. $\mathrm{Y}$ entonces] el universo de la decisión histórica, que orienta de manera duradera el destino del grupo humano, se podrá llamar auténticamente "la política" ${ }{ }^{10}{ }^{10}$

De esta manera, superando la negatividad suicida y la esperanza vacía de la utopia inrealizable, Ricoeur orienta ham cia la utopía esperanzadora y además realizable de la conciliación humana, de la re-conciliación a través de la re-flexión filosófica (ontológica, antropológica y ética) que realiza la racionalidad y la voluntad políticas encaminadas hacia el bien común. El futuro del hombre se verá iluminado por estas condiciones de su posibilidad que adelanta Ricoeur como una pro-fecía desde el pasado y el presente hacia el futuro de la historia humana. Trata de conjuntar la arqueología y la teleología o escatología. Por- 
que la escatología es imprescindible. Es la guia del proceso humano, el decantamiento de la reflexión ontológica, antropológica, moral y política que nos permite avanzar, superando los lazos deterministas y negativos que adjudicamos muchas veces a nuestros orígenes, a nuestra arqueología individual y social.

Veamos, finalmente, cuál es la idea de Ricoeur acerca del compromiso político efectivo y concreto para modelar el destino y sesgo de nuestra historia.

\section{El compromiso politico para un futuro mejor}

De acuerdo con lo que hemos dicho, el futuro óptimo será el de una socialización y personalización adecuadas del hombre, si somos fieles a la razón, esto es, al ser y al bien. Pero fácilmente se acusaria a Ricoeur -como a todo filósofo reflexivo- de moralista más bien que hombre de acción, si no va más allá de las urgencias del momento presente y si no atiende a la no menos urgente obligación de pensar nuestro futuro, de manera reflexiva. Eso nos guiará en la práctica concreta, que es igualmente perentoria.

Sin embargo, Ricoeur no se queda en dar consejos paliativos y en olvidarse del problema. Nos dice: "Jamás se ha terminado de resistir a la ruptura del interior y del exterior. De tal manera está uno inclinado a separar del curso efectivo de la acción y de la historia un islote de moralidad que es más profesada que actuada, y a definir un hombre interior, piadoso y bueno, que sería distinto de las relaciones exteriores entre los hombres en el trabajo, en la ciudad, al nivel de las naciones y de las razas"."

En lugar de mero exterior y mero in- terior (compromiso y reflexion), hay que postular dos momentos en el compromiso político: el de la adhesión a la racionalidad de la sociedad y el de la acción para conseguir la salvación de la sociedad que se ha captado en crisis. El compromiso es también interior, no sólo activismo exterior, en la búsqueda del orden social. Para buscar ese orden Ricoeur propone una relación entre fe y política; así la inspiración, que puede ser utópica, se aúna a la intención de realización de lo creído y esperado. Como filósofo cristiano, Ricoeur declara: «[...] debo expresar al nivel de las instituciones, de las formas de trabajo y de apropiación, la identidad del amor al prójimo y del amor a Dios; debo simbolizar por la búsqueda de la justicia económica y social la espera del Reino de Dios. Hay muchísimas maneras de ejencer este arte de signos en el plano político. El objetivo primordial de los cristianos es preservar la tensión de una historia que se hunde, renovar su visión revolucionaria por su propia vehemencia pmfética».12

El futuro del hombre (social, econón mico y político) ha de ser afrontado con ese compromiso integrador de lo interior y lo exterior (teoría y praxis); siempre mirando hacia la teleología o escatología humana. Esta exigencia de la escatología además de la arqueología es tal vez lo que marca la diferencia fundamental entre la hormenéutica de Ricoeur y la hermenéutica (y la filosofía) del psicoanálisis, como lo hemos podido apreciar. Según Ricoeur, el psicoanálisis es una hermenćutica incompleta del hombre, porque sólo atiende a su arqueología. Debe poder integrar de algún modo la escatología del mismo para aspirar a constituirse como un instrumento de plenificación del ser humano. 


\title{
NOTAS
}

1. Cfr. Ricoeur, P.: Tiempo y namación, I: Contiguración del tiempo en el relato historico, Madrid, Cristiandad, 1987, p. 63 .

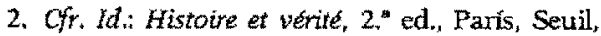
1965 , pp. 96 y 98 .

3. Tal es lo que expone Ricoeur en Etat et violence, conferencia dictada en el Foyer John Knox, de Ginebra, en 1957.

4. Cfr. Zuidema, 5.U. "Original Affirmation and Theological Eschatology in Patl Ricoeur's Thought, especially in his Histore et veritè, en Communication and Confrontation, Kampen (Nederland), J.N. Kok, Lid., pp. 289 ss.

5. Cfr. Ricoewr, P.: "la paradoxe politique", en Esprit, 1957.

6. Fsto lo expresa Ricoeur dia manera muy agu- da en Tiempo y naracion, II: Configuación del tiempo en el relato de ficcion, Madrid, Cristiandad, 1988, pp. 232 ss., donde examina En busca del tiempo perdido, de Marcel Proust.

7. Cfr. Maceiras, M.: "Paul Ricoeur: una ontologia militantew, en Pensamiento, 32 (1976), 131-156.

8. Ricoeur, P.: *Negativite et affirmation ontologiques, en Histoire et vérité.

9. Secretan, Ph.: "La pensée politique de Paul Ricoeur", en Verité et pouvorr, Lausana, l'Âge d'Homme, 1968 , p. 121.

10. $1 d$, p. 128.

11. Ricoeur, P.: "Christianisme prophétiques, en V.AA.: Les chretiens et la politique, Paris, Eds. du Temps Pressent, 1947, p. 13

12. Ibid.

\section{Apuntes sobre la recepción de la fenomenología en España}

\author{
JAVIER LERÍN RIERA \\ Sociedad Española de Fenomenologia
}

El tema que nos ocupa en este breve cstudio es cuestión que presenta sus problemas, pues acometer la tarea que el mismo supone implica, de inicio, tener que delimitar qué comprensión de la fenomenología va a ser la encargada de guiar nuestro trabajo. Con ello no hacemos tanto mención a la interpretación personal que de la doctrina o doctrinas fenomenológicas podamos tener —o pensemos que debería tenerse- como a la misma necesidad de decidir si puede y debe hablarse de la existencia de una o varias fenomenologias. Querer tratar la recepción de la fenomenología en nuestro país conlleva, pues, determinar si vamos a limitar nuestra comprensión de lo que pueda ser entendido como sfenomenología» al pensamiento y la obra de Edmund Husserl -su fundador-o si, por el contrario, vamos a aceptar la existencia de otras fenomenologías. Naturalmente, no podemos negar que el pensamiento de Heidegger y Scheler (por tomar dos ejemplos paradigmáticos) se encuentra de cierta manera emparentado -expresémoslo así- con la filosofía husserliana a pesar de que el propio Husserl afirmara que el camino tomado por el filosofar propio de tales autores fuera contrario a la fenomenología. Por ello, tal vez debiera ser necesario pararse a considerar si ambos pueden o deben ser tenidos por fenomenólogos plenos si enfrentamos la globalidad de su obra con la de Husserl y comparamos entre sí las conclusiones últimas que de cada una de ellas se derivan. Como se comprenderá, la cuestión exigiría una discusión previa que excedería con mucho el 